\title{
Comparison of Two Protocols for Management of Placenta Accreta at a Tertiary Care Center in Pakistan
}

\author{
${ }^{1}$ Rubina Izhar, ${ }^{2}$ Samia Husain, ${ }^{3}$ Suhaima Tahir, ${ }^{4}$ Sonia Husain
}

\section{ABSTRACT}

Objectives: To evaluate the morbidity of placenta accreta when managed by two different protocols.

Materials and methods: All women with placenta accreta coming to Abbasi Shaheed Hospital were included and divided in two groups. Group I included all women with accreta who were managed by lower segment transverse incision in the year 2013. Group II included all women whose accreta was dealt with classical incision in the year 2014. Morbidity from placenta accreta in all these cases was assessed.

Results: A total of 4220 deliveries took place during study. Placenta accrete was diagnosed in 24 cases (incidence $=$ $0.0056 \%$ ). Mean age of patients in group II was $28.58 \pm 3.28$ years and in group I was $29.75 \pm 2.18$ years.

Blood products were received by $9(75 \%)$ patients in group I, and by $1(8.33 \%)$ in group II $(p=0.002)$. Intensive care unit admissions in group I were $75 \%$ and $25 \%$ in group II $(p=0.014)$. Renal sequelae occurred in 7 women in group I (58.3\%) whereas none were observed in group II $(p=0.002)$. The mean duration of hospital stay was $9.83 \pm 2.95$ days in group I and $2.75 \pm 1.215$ days in group II.

Conclusion: Prevention of massive hemorrhage is the key factor in reducing maternal morbidity in placenta accreta cases.

Clinical significance: Dealing with accreta via midline incision in low resource settings leads to reduced morbidity.

Keywords: Accreta, Classical, Hemorrhage, Morbidity.

How to cite this article: Izhar R, Husain S, Tahir S, Husain S. Comparison of Two Protocols for Management of Placenta Accreta at a Tertiary Care Center in Pakistan. J South Asian Feder Obst Gynae 2017;9(1):18-24.

\section{Source of support: Nil}

Conflict of interest: None

Date of received: 20 October 2016

Date of acceptance: 15 December 2016

Date of publication: January 2017

\footnotetext{
${ }^{1}$ Professor, ${ }^{2,4}$ Trainee, ${ }^{3}$ Student

1,2,4 Department of Obstetrics and Gynecology, Abbasi Shaheed Hospital, Karachi, Sindh, Pakistan

${ }^{3}$ Department of Research, Dow Medical College, Karachi, Sindh Pakistan

Corresponding Author: Samia Husain, Trainee, Department of Obstetrics and Gynecology, Abbasi Shaheed Hospital Karachi, Sindh, Pakistan, Phone: +923453120015, e-mail: samiahusain_scorpio@hotmail.com
}

\section{INTRODUCTION}

Placenta accreta or morbidly adherent placenta is characterized by abnormal placental adherence secondary to decidual defect. It is classified into three main types placenta accrete adhered to myometrium, placenta increta invading myometrium and placenta percreta breaching uterine serosa with or without involvement of bladder. $^{1}$

The reported incidence of placenta accrete has increased from 1:2510 in the 1980s to 1:533 in 2002 and to $1: 210$ in $2006^{2,3}$ Ireland saw a $34 \%$ increase in placenta accrete from 2005 to 2010, possible culprit being the increase in cesarean section rate. ${ }^{4}$ In Pakistan placenta accrete is now seen more frequently. A study from Lahore reports the incidence of 1 in 695 deliveries. ${ }^{5}$ Ayesha Arif reported 1 in 131 deliveries. $^{6}$

Obstetric hemorrhage is one of the most common causes of maternal morbidity and mortality worldwide, and abnormal placentation, including placenta accreta, is currently the most common indication for peripartum hysterectomy. ${ }^{7}$ A study from Dublin reported Placenta accrete as the most common indication of peripartum hysterectomy rising from a mere 5.4 to $46.5 \%$ over four decades. ${ }^{8}$ Although uterine salvage has been proposed in the literature, but most often hysterectomy cannot be avoided.

Morbidity and mortality after peripartum hysterectomy are significant. A nationwide sample of women in the United States who underwent obstetric hysterectomy reported a mortality rate of $1.0 \%$, whereas other studies have described perioperative death rates of 1 to $6 \% .{ }^{9}$

Traditionally, cesarean section was performed through lower segment transverse incision, and after delivery of the baby, placental separation was attempted. If placenta failed to separate or placental bed continued to bleed, a hysterectomy was performed. Debate remains over the optimal management of placenta accreta, increta, and percreta: If the placenta fails to separate after delivery, leaving it in place and proceeding with either a hysterectomy or conservative management, rather than trying to separate it, is currently recommended by the Royal College of Obstetricians and Gynecologists (RCOG). ${ }^{10}$ The American College of Obstetricians and Gynecologists currently make no specific recommendations regarding attempted placental separation. 
Classical cesarean section finds few indications in modern obstetric practice; the main hindrance is its predisposition to scar rupture in subsequent pregnancies $(12 \%)$ as compared to lower segment transverse incision $2 \%{ }^{11}$ Classical incision provides better visibility and avoids uterine vessels that are engorged in placenta accreta, and meticulous bladder dissection is not needed. ${ }^{12}$

It also allows delivery of baby with minimal trauma and compromise as placenta is not disturbed. Neonatal anemia and fetal exsanguination is also minimized.

The midline approach is anticipated to avoid cutting the placenta, prevent intraoperative bleeding and give operator enough time to decide optimum course of action, i.e., hysterectomy or salvage. It is also expected that minimizing blood loss intraoperatively would reduce morbidity from placenta accreta.

We hereby describe the morbidity form placenta accreta when managed by two different protocols in our unit.

\section{MATERIALS AND METHODS}

The present study was carried out during 2-year periods from January 1, 2013, to December 31, 2013, and January 1, 2014, to December 31, 2014, in the Department of Obstetrics and Gynecology, Abbasi Shaheed Hospital, affiliated with Karachi Medical and Dental College, Karachi, Pakistan. Study design was cross-sectional descriptive comparative. Subjects included were women with uterine scarring due to previous cesarean section and diagnosed with placenta accreta. Diagnosis was made during the antenatal period through scans and Doppler ultrasound. Patients with undiagnosed accreta were excluded from the study as adequate resources were not mobilized for such patients. Patients with uterine malformations were also excluded. The study population was divided into two groups, groups I and II. Group I included all women with accreta who were managed by lower segment transverse incision in the year 2013 as per unit protocol (discussed below) for the management of placenta accreta. Group II included all women whose accreta was dealt with classical incision in the year 2014. The high morbidity associated with the former approach led to change in the hospital protocol (new protocol discussed below) for managing accreta.

Group I comprised of 12 women, admitted to our unit with accreta diagnosed on their scan. The unit protocol was as follows during the year 2013. All patients were operated by senior obstetrician, and multidisciplinary team approach was followed. Informed consent was taken, which included consent for hysterectomy. All cases were operated under general anesthesia and prophylactic antibiotics were administered prior to the procedure. Skin incision used was Pfannenstiel, and abdomen was opened layer by layer till uterus was reached. Uterus was opened by lower segment transverse incision, and baby was delivered by going through the placenta. Placental separation was attempted. After delivery of the placenta wholly or piecemeal, placental site was inspected for bleeders. Compression sutures and manual compression was used to arrest bleeding. If bleeding arrested, uterine salvage was taken into consideration. These measures were attempted for a maximum of 15 minutes, after which hysterectomy was performed to arrest hemorrhage.

Group II included 12 patents in which the new protocol was used. The new protocol differed from the old protocol in the following five aspects: (1) All patients were opened via up-and-down incision on abdomen. (2) Uterus was opened by midline classical incision avoiding the placenta. (3) Baby was delivered by breech extraction. (4) After delivery of baby, uterus was exteriorized. Placenta was allowed to deliver from the incision line after syntocinon was given 10 IU IV. (5) Vigorous attempts to separate the placenta were not made if the placenta did not deliver after 10 minutes or the uterine salvage was not possible clamps for hysterectomy were applied.

Uterine salvage was considered unlikely if placenta did not give away in 10 minutes, the placenta occupied more than half of the anterior wall of uterus, and lower segment or hemodynamic status of the patient started deteriorating.

Patients were shifted to Intensive Care Unit (ICU) if the hemodynamic status deteriorated. Patients crashed during the procedure and epinephrine was used to normalize blood pressure, and saturations were not maintained.

For both the study periods, abdominal packing was done if after all efforts hemostasis could not be secured. Major bleeders were tied with chromic catgut number 1 and 6 to 8, 6-meter gauze rolls were moistened with normal saline and put into the abdominal cavity to arrest bleeding from oozers, drain was placed inside, and rectus muscle was closed. Rectus sheath and skin incision were closed by two to three interrupted sutures. Sterile dressing was done. Pack was removed after 24 to 48 hours under general anesthesia. All patients with abdominal packing were put on triple regimen: Injection ceftriaxone $1 \mathrm{gm}$ IV 12 hourly, inj. gentamycin 80 mg IV 8 hourly, and inj. metronidazole $100 \mathrm{~mL}$ IV 8 hourly.

Informed consent regarding use of operative records was obtained from all participants. A performa was designed to collect all relevant information. It included basic demographic details like age of parturients, gestational age at the time of delivery, obstetrical history (parity, history of dilation and curettage number of 
Table 1: Basic details of patients

\begin{tabular}{|c|c|c|c|c|c|c|c|}
\hline & \multicolumn{2}{|c|}{ Age } & \multicolumn{3}{|c|}{ Gestational age } & \multirow[b]{2}{*}{$p$-value } \\
\hline & & Mean & Standard deviation & $p$-value & Mean & Standard deviation & \\
\hline \multirow{2}{*}{$\begin{array}{l}\text { Uterine } \\
\text { incision }\end{array}$} & Lower segment transverse & 29.75 & 2.18 & 0.317 & 34.42 & 1.16 & 0.846 \\
\hline & Upper segment midline & 28.58 & 3.29 & & 34.33 & 0.89 & \\
\hline
\end{tabular}

cesareans), and uterine incision. Morbidity markers used in study were duration of surgery, need for blood transfusion, injury to viscera, maternal and fetal outcome, need for ICU admission, need for reopening renal sequelae , and duration of hospital stay. These variables were taken into account and were then analyzed, and their differences were compared to evaluate the morbidity from both incisions. Data were collected by corresponding author, and strict vigilance was observed. All patients' families were counseled beforehand about need for hysterectomy and risks for uterine rupture in subsequent pregnancy, and need for hospital delivery in future were explained. Written and informed consent was taken. All patients received prophylactic antibiotics and were operated under general anesthesia by senior obstetricians.

All responses were entered into Statistical Package for the Social Sciences version 15.0 (IBM, Armonk, NY, USA) and data was analyzed. The chi-square and Fisher's exact test were used for categorical variables. The t-test was applied for comparison of mean values. Frequencies, means, and standard deviations were computed for the study variables. The statistics thus obtained were fit into the appropriate group, and their differences were compared. The results were considered statistically significant when $\mathrm{p} \leq 0.05$.

\section{DETAILS OF ETHICAL APPROVAL}

The ethical review board of the institution approved the study (IRB: 030/15).

\section{RESULTS}

A total of 4220 deliveries took place during the study period. Placenta accrete was diagnosed in 24 cases giving an incidence of 1 in $200(0.0056 \%)$. Mean age of patients in group II was $28.58 \pm 3.28$ years and in group I was $29.75 \pm 2.18$ years. The mean gestational age was $34.42 \pm 1.16$ in group I and $34.33 \pm 0.89$ weeks in group II. There was no significant difference in maternal ages $(p=0.317)$ and gestational ages $(p=0.846)$ in both the study groups (Table 1 ).

The identified obstetrical risk factors of morbidly adherent placenta are shown in Table 2. There was no statistically significant difference that could be seen in all three parameters for the two groups. Majority of women in the two groups, $91.66 \%$ in group I and $83.33 \%$ in group II, had a parity ranging 2 to $4(\mathrm{p}=0.587)$. In both
Table 2: Risk factors for morbidly adherent placenta

\begin{tabular}{|c|c|c|c|c|c|c|}
\hline & & \multicolumn{4}{|c|}{ Uterine incision } & \multirow[b]{3}{*}{$p$-value } \\
\hline & & \multicolumn{2}{|c|}{$\begin{array}{l}\text { Lower segment } \\
\text { transverse }\end{array}$} & \multicolumn{2}{|c|}{$\begin{array}{c}\text { Upper segment } \\
\text { midline }\end{array}$} & \\
\hline & & $n=12$ & $\%$ & $n=12$ & $\%$ & \\
\hline \multirow{2}{*}{$\begin{array}{l}\text { History of } \\
d \text { and } c\end{array}$} & Yes & 3 & 25.0 & 2 & 16.7 & \multirow[t]{2}{*}{0.615} \\
\hline & No & 9 & 75.0 & 10 & 83.3 & \\
\hline \multirow[t]{4}{*}{ Parity } & 2 & 4 & 33.3 & 3 & 25.0 & \multirow[t]{4}{*}{0.587} \\
\hline & 3 & 5 & 41.7 & 3 & 25.0 & \\
\hline & 4 & 2 & 16.7 & 5 & 41.7 & \\
\hline & 5 & 1 & 8.3 & 1 & 8.3 & \\
\hline \multirow{2}{*}{$\begin{array}{l}\text { No. of } \\
\text { cesareans }\end{array}$} & 1 & 9 & 75.0 & 9 & 75.0 & \multirow[t]{2}{*}{1.00} \\
\hline & 2 & 3 & 25.0 & 3 & 25.0 & \\
\hline
\end{tabular}

the groups $(75 \%)$ had one cesarean sections $(p=1.00)$. History of dilation and curettage was present in $25 \%$ of patients in group I, and $16.66 \%$ had a history in group II which is not statistically significant $(p=0.615)$.

When the transfusion details were compared between the two study groups, a very significant difference was seen in parameters of blood transfusion and units of blood products transfused (Table 3). Majority of the patients in group I received moderate defined according to study purpose as (5-8 units) or massive (9-12) units of blood 9 out of 12 patients $83.33 \%$, with 2 patients requiring greater than 12 units of blood, while only 1 patient out of $12(8.33 \%)$ in the group II required more than 4 units of blood $(p=0.000)$. Blood products were received by $9(75 \%)$ of patients in the group I, with 1 patient requiring cryoprecipitate as well. Compared to this, only 1 patient received fresh frozen plasma (FFP) and platelets in group II $(p=0.002)$; this reached statistical significance.

Intensive Care Unit admissions in group I were frequent with $75 \%$ needing intensive care, while only three patients $(25 \%)$ in group II were shifted to ICU $(p=0.014)$ which was comparatively higher.

No patient was reopened in group II while $75 \%$ in group I were reopened. All of these patients had abdominal packing in place to halt bleeding as a last resort, and pack had to be removed on the 2 nd postoperative day after stabilization. This proved statistically significant $\left(\mathrm{p}=0.000^{*}\right)$.

Renal sequelae and bladder injury also reached a statistical significance in both groups: 7 out of 12 in group I $(58.3 \%)$ had renal sequelae whereas none were observed in any patient in group II $(\mathrm{p}=0.002)$. Bladder injury took 
Table 3: Morbidity parameters

\begin{tabular}{|c|c|c|c|c|c|c|}
\hline & \multicolumn{4}{|c|}{ Uterine incision } & \multirow[b]{3}{*}{$p$-value } \\
\hline & & \multicolumn{2}{|c|}{ Lower segment transverse $n=12$} & \multicolumn{2}{|c|}{ Upper segment midline $n=12$} & \\
\hline & & $n$ & $\%$ & $n$ & $\%$ & \\
\hline \multirow[t]{6}{*}{ Blood products } & Nil & 2 & 16.7 & 10 & 83.3 & \\
\hline & FFP only & 0 & 0 & 1 & 8.3 & \\
\hline & FFP and platelets & 9 & 75 & 0 & 0 & 0.002 \\
\hline & FFP platelets and cryoprecipitate & 1 & 8.3 & 0 & 0 & \\
\hline & Platelets only & 0 & 0 & 1 & 8.3 & \\
\hline & Cryoprecipitate only & 0 & 0 & 0 & 0 & \\
\hline \multirow[t]{3}{*}{ Bladder injury } & Nil & 8 & 66.7 & 12 & 100 & 0.028 \\
\hline & Bladder & 4 & 33.3 & 0 & 0 & \\
\hline & Ureter & 0 & 0 & 0 & 0 & \\
\hline \multirow[t]{2}{*}{ ICU admission } & Yes & 9 & 75 & 3 & 25 & 0.014 \\
\hline & No & 3 & 25 & 9 & 75 & \\
\hline \multirow[t]{2}{*}{ Need for reopening } & Yes & 9 & 75 & 0 & 0 & 0 \\
\hline & No & 3 & 25 & 12 & 100 & \\
\hline \multirow[t]{2}{*}{ Renal sequelae } & Yes & 7 & 58.3 & 0 & 0 & 0.002 \\
\hline & No & 5 & 41.7 & 12 & 100 & \\
\hline \multirow[t]{4}{*}{ Units transfused } & Extreme (more than 12) & 2 & 16.7 & 0 & 0 & \\
\hline & Massive $(9-12)$ & 7 & 58.3 & 0 & 0 & 0 \\
\hline & Mild (1-4) & 0 & 0 & 11 & 91.7 & \\
\hline & Moderate (5-8) & 3 & 25 & 1 & 8.3 & \\
\hline
\end{tabular}

Table 4: Duration of stay and duration of surgery

\begin{tabular}{|c|c|c|c|c|c|c|c|}
\hline & & \multicolumn{2}{|c|}{ Duration of surgery } & \multicolumn{3}{|c|}{ Duration of stay } & \multirow[b]{2}{*}{$p$-value } \\
\hline & & Mean & Standard deviation & $p$-value & Mean & Standard deviation & \\
\hline \multirow[t]{2}{*}{ Uterine incision } & Lower segment transverse & 190.25 & 17.24 & 0 & 9.83 & 2.95 & 0 \\
\hline & Upper segment midline & 122.92 & 28.56 & & 2.75 & 1.22 & \\
\hline
\end{tabular}

place in four cases in group I during bladder dissection, after hysterectomy was planned. Bladder repair was done by urologist and total hysterectomy was done. A catheter was retained for 14 days in all, while no patient in classical incision group had bladder injury ( $\mathrm{p}=0.028)$.

In group I, $190.25 \pm 17.24$ minutes while in group II mean duration of surgery was $122.92 \pm 28.561$ minutes, which is significantly lower $\left(\mathrm{p}=0.000^{*}\right)$. The hospital stays differed significantly as well $\left(\mathrm{p}=0.000^{*}\right)$. The mean duration of hospital stay was $9.83 \pm 2.95$ days in group I and $2.75 \pm 1.215$ days in group II (Table 4).

\section{DISCUSSION}

Due to recent advances in modern obstetrics and current climate of litigation, cesarean section rate is on the rise worldwide. Anesthetic techniques and round the clock availability of blood products have rendered the procedure safer than before. But this comes at a price, incidence of placenta accreta, which by far is the most dreaded complication of cesarean deliveries, has risen in parallel with cesarean section rate.

The present study reports the incidence as 1 in 200 which is higher to that quoted by Ayesha Arif who reported 1 in $131 .{ }^{6}$ A study from Lahore reports the incidence as 1 in 695 which is much lower than ours. ${ }^{5}$ This high rate can probably be explained by considering the fact that because of our location we end up accepting referred cases not only from Sindh but also from Baluchistan.

This raging increase in accreta has contributed heavily toward the rates of peripartum hysterectomies worldwide. But even with the best possible management, in tertiary care centers, morbidity from hysterectomies is significant.

Magnetic resonance imaging (MRI) and ultrasound have been compared many a times, and in expert hands, the sensitivity of ultrasound scan is equally good. Maher et $\mathrm{al}^{13}$ have proposed that if Doppler shows accreta, further confirmation can be done by an MRI. In our study, all patients were diagnosed antenatally on Doppler ultrasound. We did not confirm accreta by MRI because of financial constraints, but we found that sensitivity of Doppler in our study was $100 \%$.

Risk factors associated with placenta accreta are multiparity, increased age, scarred uterus, and history of previous dilation and curettage. ${ }^{14}$ In the study by 
Nargis Iqbal et al, where etiological factors for accreta were determined, $77 \%$ were multigravidas and $23 \%$ were grand multigravidas; similarly in our study, no patients were primigravidas. They reported that $84.61 \%$ of women with placenta accreta were between 31 and 35 years of age; in our series mean age was 28.58 years in group II and 29.75 years in group $\mathrm{I}$.

Placenta previa and placenta accreta are often seen together in patients, Ayesha Arif ${ }^{6}$ reports $75 \%$ of accreta to coexist with placenta previa. In our study all patients had previa with accreta.

In our study $75 \%$ had accreta in both the groups after one cesarean compared to Nargis et al where $46 \%$ of the patients had previous two sections and 38.5\% had previous three cesareans. ${ }^{5}$ In our study, rate of accreta after one cesarean section was alarmingly high when compared with reported literature worldwide. Poor sterilization and surgical technique can be a contributing factor as majority of the patients had their first cesarean in small peripheral setups.

Risk of placenta accreta also increases with history of dilation and curettage. In our study, $16.7 \%$ in group II and $25 \%$ in group I had a history of prior curettage which is similar to that quoted by Nargis et al. ${ }^{5}$

Bleeding from placental vessels causes massive hemorrhage and need for emergent hysterectomy arises. Afia Ansar et al compared delayed hysterectomy for placenta accreta via classical incision in which the placenta is left in situ and hysterectomy is performed later with conventional hysterectomy performed through lower segment transverse incision. This study reports a reduction in transfusion rate in the group managed by delayed hysterectomy. Their transfusion rate was $2.93 \pm 1.16$ units which is comparable to our study, but with this approach mean hospital stay was 32 days, compared with mean stay of 2 days in our study. It should also be emphasized that all these patients were reopened whereas in our study no patient required repeat laparotomy in the arm where classical incision was used.

In the second arm of the same study, where patients were managed with a lower segment transverse cesarean, and an average 7 pints of blood were transfused which is comparable to the blood transfused in the arm of our study where lower segment transverse incision was used, but is higher than the arm where classical incision was used. Advantage of placenta sparing midline incision with concomitant hysterectomy can be clearly appreciated by comparing our findings with the other arm of the study. ${ }^{15}$

A study from UK has compared attempting placental separation at the time of cesarean with no attempt to separate placenta. They found that the required transfusion is between 3 and 29 units of packed red blood cells. Median units of packed red blood cells transfused were 7 units in both arms; ${ }^{16}$ in our protocol, when placental separation was attempted transfusion rates were high as well.

A study from Lahore, where placenta sparing high transverse incision was used, transfusion of 4 pints on an average and a mean hospital stay of 6 to 8 days was reported. ${ }^{5}$ Our study shows a mean stay duration of $2.75 \pm 1.215$ days in the arm where classical incision was done, which is lower.

Mean duration of surgery was $122.92 \pm 28.561$ minutes for classical approach in our study which is significantly lower than the one reported for peripartum hysterectomies for accreta in literature. The median reported operative time was 154 minutes (interquartile range, 125-191) for all cases. ${ }^{17}$ The operating time in lower segment transverse incision arm in our study was higher due to the greater blood loss, and the subsequent strategies instituted to halt the bleeding.

No patient died in the arm where midline incision was instituted, but we lost four patients in the arm where lower segment transverse incision was used $(p=0.028)$. Reported mortality rate from peripartum hysterectomy is between 1 and $6 \%$ worldwide. ${ }^{9}$ A study from India reports mortality rate of $30 \%$ in patients with placenta accrete. ${ }^{18}$

No patient suffered from renal sequelae in the classical incision arm, which can be attributed to the significantly lower blood loss obviating the need for transfusion. Majority of the patients were transfused only 2 units. This reduction in blood loss in turn can be due to the technique described. In the other arm of our study, seven patients had renal sequelae which reached statistical significance (0.002). In a data analysis of peripartum hysterectomy by Zelop et al, ${ }^{19}$ which included 75 cases of peripartum hysterectomy due to accreta, it has been stated that hemorrhagic shock occurs in over half of all cases, and coagulopathy or disseminated intravascular coagulation occurs in more than $25 \%$ of patients, and clear advantage can be seen with our approach.

In a study, where uterus was opened via lower segment cesarean section for management of accreta, 23\% women had bladder injury. ${ }^{15}$ Four patients (33.33\%) in the lower segment transverse incision arm had bladder damage which is comparable to that reported by Afia Ansar et al. No patient in the classical incision group had bladder damage. The classical incision avoids bladder altogether. A study where ureteric stents were used, no injury to ureters was reported, and authors have recommended stenting to avoid ureteric injury. ${ }^{20}$ In our study, only three patients who were operated electively got stenting done, whereas for the other $67 \%$ patients who underwent surgery as emergency procedures stenting could not be arranged.

Uterine sparing management options have been in practice since a long time. However, they all have their 
shortcomings. A large multicenter study indicates that $71 \%$ of accreta cases eventually have a hysterectomy, and though elective procedures give surgeons a chance to act in a well-controlled manner, hysterectomies and subsequent morbidity due to accreta continue to be a concern. ${ }^{17}$

Leaving the placenta inside leads to reopening the patient, and it also requires antibiotic coverage and doses of methotrexate which in itself are harmful but still holds a place when percreta is diagnosed. A review of the literature showed that despite initial conservative management, $40 \%$ of women subsequently require emergency hysterectomy, and $42 \%$ experience major morbidity. ${ }^{21}$

Oyelese et $\mathrm{al}^{22}$ have recommended that patients with placenta accreta should have planned cesarean sections and abdominal hysterectomy should be performed without attempting placental separation. Hysterectomy, therefore, continues to be the definitive treatment of placenta accreta.

Hysterectomy due to accreta leads to loss of fertility at a young age for most women that raises numerous questions regarding the current management. Argument that if uterus is conserved after a classical cesarean section would lead to scar rupture in subsequent pregnancy should be weighed against the fact that such patients should then not be given a trial of vaginal birth after cesarean section and a hospital delivery should be considered with steroid cover at 34 weeks.

Another point that needs discussion is that any incision other than the low transverse incision, conventionally used in cesarean sections, is in upper segment of uterus, be it high transverse placenta sparing incision or the classical incision. The rupture rate from high transverse incision has not yet been assessed. Until data regarding this incision becomes available the two can be treated as equivalent. Moreover, in order to spare placenta completely, for a high transverse incision, ultrasound mapping is required during surgery. It requires availability of equipment and expertise in operating room which is not always a possibility in majority of centers.

\section{CONCLUSION}

Prevention of massive hemorrhage is the key factor in reducing maternal morbidity in placenta accreta cases. We propose adoption of a technique that avoids sudden hemorrhage with delivery of baby and allows the surgeon sufficient time to decide/proceed with further course of action thus optimizing outcome in case of placenta accreta.

\section{CLINICAL SIGNIFICANCE}

Dealing with accreta via midline incision in low resource settings leads to reduced morbidity.

\section{REFERENCES}

1. Kean L. Antepartum haemorrhage. In: Luesley, DM; Baker, PN, editors. Obstetrics and gynaecology: An evidence-based text for MRCOG. 2nd ed. London: HodderArnold; 2010. p. 316-317.

2. Wu S, Kocherginsky M, Hibbard JU. Abnormal placentation: Twenty year analysis. Am J Obstet Gynecol 2005 May;192(5):1458-1461.

3. Silver RM, Landon MB, Rouse DJ, Leveno KJ, Spong CY, Thom EA, Moawad AH, Caritis SN, Harper M, Wapner RJ, et al. Maternal morbidity associated with multiple repeat cesarean deliveries. Obstet Gynecol 2006 Jun;107(6):1226-1232.

4. Upson K, Silver RM, Greene R, Lutomski J, Holt VL. Placenta accreta and maternal morbidity in the Republic of Ireland, 2005-2010. J Matern Fetal Neonatal Med 2014 Jan;27(1):24-29.

5. Iqbal N, Sohail N, Tayyab M. Placenta accreta—still a dilemma. Ann King Edward Med Uni 2012 Jul-Sep;18(3):250-254.

6. Arif A. Study of frequency and outcome of management in pregnancies complicated by Morbid adherence of placenta. Pak Armed Forces Med J 2010 Dec;4(12):131-136.

7. Pacheco LD, Gei AF. Controversies in the management of placenta accreta. Obstet Gynecol Clin North Am 2011 Jun;38(2):313-322.

8. Flood KM, Said S, Geary M, Robson M, Fitzpatrick C, Malone FD. Changing trends in peripartum hysterectomy over the last 4 decades. Am J Obstet Gynecol 2009 Jun;200 (6):632.e1-6.

9. Perez-Delboy A, Wright JD. Surgical management of placenta accreta: to leave or remove the placenta? BJOG. 2014 Jan;121(2):163-169; discussion 169-170.

10. Royal College of Obstetricians and Gynaecologists. Placenta praevia, placenta praevia accreta and vasa praevia: Diagnosis and management. Green-top Guideline No. 27. London: RCOG, January 2011.

11. Royal College of Obstetricians and Gynaecologists. Birth after previous Cesarean birth. Green-top Guideline No. 45. London: RCOG, Feburary 2007.

12. King M, Bewes PC, Cairns J, Thornton J, editors. Primary surgery: Volume one: non-trauma. New York: Oxford University Press; 2009.

13. Maher MA, Abdelaziz A, Bazeed MF. Diagnostic accuracy of ultrasound and MRI in the prenatal diagnosis of placenta accreta. Acta Obstet Gynecol Scand 2013 Sep;92(9):1017-1022.

14. Miller DA, Chollet JA, Goodwin TM. Clinical risk factors for placenta previa-placenta accreta. Am J Obstet Gynecol 1997 Jul;177(1):210-214.

15. Ansar A, Malik T, Shuja S, Khan S. Hysterectomy as a management option for morbidly adherent placenta. J Coll Physicians Surg Pak 2014 May;24(5):318-322.

16. Fitzpatrick KE, Sellers $S$, Spark $P$, Kurinczuk JJ, Brocklehurst $P$, Knight M. The management and outcomes of placenta accreta, increta, and percreta in the UK: a population-based descriptive study. BJOG 2014 Jan;121(1):62-70; discussion 70-71.

17. Shellhaas CS, Gilbert S, Landon MB, Varner MW, Leveno KJ, Hauth JC, Spong CY, Caritis SN, Wapner RJ, Sorokin Y, et al. The frequency and complication rates of hysterectomy accompanying cesarean delivery. Obstet Gynecol 2009 Aug;114 (2 Pt 1):224-229.

18. Aggarwal R, Suneja A, Vaid NB, Yadav P, Sharma A, Mishra K. Morbidly adherent placenta: a critical review. JObstet Gynaecol India 2012 Feb;62(1):57-61.

19. Zelop CM, Harlow BL, Frigoletto FD, Safon LE, Saltzman DH. Emergency peripartum hysterectomy. Obstet Gynecol 1993 May;168(5):1443-1448. 
20. Eller AG, Porter TF, Soisson P, Silver RM. Optimal management strategies for placenta accreta. BJOG 2009 Apr;116(5): 648-654.

21. Pather S, Strockyj S, Richards A, Campbell N, de Vries B, Ogle R. Maternal outcome after conservative management of placenta percreta at caesarean section: a report of three cases and a review of the literature. Aust N Z J Obstet Gynaecol 2014 Feb;54(1):84-87.

22. Oyelese $Y$, Smulian JC. Placenta previa, placenta accreta, and vasa previa. Obstet Gynecol 2006 Apr;107(4):927-941. 